FEDERAL RESERVE BANK OF SAN FRANCISCO

WORKING PAPER SERIES

\title{
Fiscal Foresight and Perverse Distortions to Firm Behavior: Anticipatory Dips and Compensating Rebounds
}

\author{
Robert S. Chirinko \\ University of Illinois at Chicago \\ Daniel J. Wilson \\ Federal Reserve Bank of San Francisco
}

March 2023

Working Paper 2021-15

https://www.frbsf.org/economic-research/publications/working-papers/2021/15/

\section{Suggested citation:}

Chirinko, Robert S., Daniel J. Wilson. 2023 "Fiscal Foresight and Perverse Distortions to Firm Behavior: Anticipatory Dips and Compensating Rebounds," Federal Reserve Bank of San Francisco Working Paper 2021-15. https://doi.org/10.24148/wp2021-15

This paper was previously circulated under the title "Fiscal Foresight and Real Distortions to Firm Behavior: Anticipatory Dips and Compensating Rebounds."

The views in this paper are solely the responsibility of the authors and should not be interpreted as reflecting the views of the Federal Reserve Bank of San Francisco or the Board of Governors of the Federal Reserve System. 


\title{
Fiscal Foresight And Perverse Distortions To Firm Behavior: Anticipatory Dips And Compensating Rebounds
}

\author{
Robert S. Chirinko and Daniel J. Wilson*
}

February 2023

\begin{abstract}
* Acknowledgements: Financial support from the Federal Reserve Bank of San Francisco and the W.E. Upjohn Institute for Employment Research, a discussion with Francesco Lippi, and comments from Guido Lorenzoni are gratefully acknowledged. The Einaudi Institute of Economics and Finance provided a most pleasant environment in which to prepare this paper. All errors and omissions remain the sole responsibility of the authors, and the conclusions do not necessarily reflect the views of the organizations with which they are associated or the sponsoring organizations.
\end{abstract}

Robert S. Chirinko

Department of Finance

2333 University Hall

University of Illinois at Chicago

601 South Morgan (MC 168)

Chicago, Illinois 60607-7121

PH: 3123551262

FX: 3124137948

EM: chirinko@uic.edu
Corresponding Author

Daniel J. Wilson

Federal Reserve Bank of San Francisco

Mail Stop 1130

101 Market Street

San Francisco, CA 94105

PH: 4159743423

FX: 4159742168

EM: Daniel.Wilson@sff.frb.org 


\title{
Fiscal Foresight And Perverse Distortions To Firm Behavior: Anticipatory Dips And Compensating Rebounds
}

\begin{abstract}
We study the conditions under which fiscal foresight - forward-looking agents anticipating future policy changes - results in perverse economic behavior through unintended intertemporal tradeoffs. Somewhat surprisingly, fiscal foresight by itself is far from sufficient for policyinduced incentives to perversely distort firm behavior. Rather, we show that there are two additional sets of conditions, at least one of which must hold to generate perverse behavior: (i) storable output, diminishing returns, and a non-competitive output market; (ii) "rolling base" policy design and storable output. These conditions suggest that the estimated impacts of fiscal policies may be sensitive to underlying economic or legislative characteristics and that policies targeted to specific firms or industries with unique characteristics may not be generalizable.
\end{abstract}

Keywords: Fiscal foresight, intertemporal tradeoffs, real distortions, fiscal policy

JEL codes: E62 (fiscal policy), H20 (taxation, subsidies, and revenue: general) 


\section{Fiscal Foresight And Perverse Distortions To Firm Behavior: Anticipatory Dips And Compensating Rebounds}

\section{Table Of Contents}

I. Introduction

II. Optimization Problem

III. First Order Conditions And The Steady-State

IV. Intertemporal Distortions From A Delayed Tax Credit (DTC):

Sufficient Conditions In The Economic Environment

V. Intertemporal Distortions From A Delayed Tax Credit (DTC):

Introducing Inventory Costs

VI. Intertemporal Distortions From A Delayed Tax Credit (DTC):

Sufficient Conditions In The Fiscal Policy Design

VII. Discussion

VIII. Summary

References 


\section{Fiscal Foresight And Perverse Distortions To Firm Behavior: Anticipatory Dips And Compensating Rebounds}

\section{Introduction}

Consider a situation where a firm operating in a competitive market anticipates the government will soon adopt a generous employment tax credit. Economic intuition suggests that, for the profit-maximizing firm, employment and production should be reduced today, while labor costs are high, and increased after the credit goes into effect, when labor costs will be lower. An implicit assumption underlying that intuition is that the firm has an inventory stock that can be drawn upon to meet today's demand and replenished later when the tax credit is effective. ${ }^{1}$

Unfortunately, that economic intuition is misleading because, for a firm using a linear technology or operating in a competitive market, there is no reason to violate the first-order conditions for production efficiency. In fact, for the anticipation of tax policy tomorrow to affect economic decisions today requires a particular set of conditions that are far from universal. This paper studies the conditions under which fiscal foresight - forward-looking agents anticipating future policy changes - results in perverse economic behavior for a profit-maximizing firm responding to incentives and making intertemporal tradeoffs opposite to the intention of policymakers. Somewhat surprisingly, fiscal foresight is not sufficient for policy-induced incentives to perversely affect firm behavior today. We identify two alternative sets of sufficient conditions, one related to the economic environment and the other to the design of the fiscal initiative. At least one of these sets of conditions must hold for fiscal foresight to generate perverse distortions. These conditions are far from universal and suggest that the estimated impacts of fiscal policies may be sensitive to underlying economic or legislative characteristics and that policies targeted to specific firms or industries with unique characteristics may not be generalizable.

Fiscal policies are frequently anticipated before they go into effect. Based on the narrative accounts of Romer and Romer (2010b), Mertens and Ravn (2012) find that a little more

\footnotetext{
${ }^{1}$ Another example is the so-called "Green Paradox," the idea that fossil fuel producers, if they anticipate a carbon tax tomorrow, might extract more fossil fuels today, before they face the tax, and hence perversely cause an increase in carbon emissions (Sinn, 2012; Van der Ploeg and Withagen, 2020).
} 
than half of federal tax changes from 1947-2006 were anticipated; the median anticipation lag was six quarters.

Anticipation arises for two reasons: a lag between when the policy is formally adopted and when it is implemented (implementation lag) and a lag between when the policy is discussed, deliberated, and amended and formally adopted (preview lag). Fiscal foresight occurs when forward-looking agents anticipate a future policy change due to these lags.

The quantitative importance of fiscal foresight is a key policy question and has been the subject of many previous empirical studies that distinguish between anticipated and unanticipated changes in aggregate fiscal policy. The results are mixed. Auerbach and Gale (2009); Caggiano, Castelnuovo, Colombo, and Nodari (2015); Kriwoluzky (2012); Leduc and Wilson (2013); Leeper, Richter, and Walker (2012); Leeper, Walker, and Yang (2013), Mertens and Ravn (2011, 2012); Ramey (2011); and Yang (2005), among others, report a significant role for anticipated shocks in terms of their co-movements with macroeconomic activity, pointing to the importance of fiscal foresight. By contrast, the VAR analyses of fiscal shocks by Blanchard and Perotti (2002) and Perotti (2012) and the single-equation narrative analysis by Romer and Romer (2010a) do not support the quantitative importance of fiscal foresight. Ramey (2011, p. 3) documents "how failing to account for the anticipation effect can explain some of the differences in the empirical results" from the VAR and narrative approaches.

To begin to better understand these disparate results, this paper examines the theoretical underpinnings of fiscal foresight in the context of business tax incentives. The policy stimulates economic activity when implemented according to standard channels. Here we are interested in the effects of fiscal foresight that arise when there is an implementation lag and may distort firm behavior through perverse intertemporal tradeoffs. Fiscal foresight and anticipation of the implementation date do not necessarily impact real variables such as factor demands, output, and sales. Moreover, when there is an impact, it usually does not result in distortions during the implementation period. We derive two alternative sets of sufficient conditions for fiscal foresight to distort firm behavior through perverse intertemporal tradeoffs. One set of conditions involve characteristics of the economic environment: storable output, diminishing returns, and a 
non-competitive output market; ${ }^{2}$ if all three of these conditions are met, fiscal foresight will lead to intertemporal distortions. Another set of sufficient conditions for such distortions from fiscal foresight relates to the design of the fiscal policy itself, as well as storable output.

Our theoretical framework focuses on an anticipated change in a tax policy that differentially affects firm demand for a factor of production. We will call this factor "labor", consider the tax policy a "credit" on labor (i.e., a reduction in an existing tax or an introduction of a subsidy or a negative tax), and refer to this policy as a delayed tax credit (DTC). A partial equilibrium model is developed that allows us to identify the conditions required for fiscal foresight to affect real firm behavior without having to make incidental assumptions and calibrate parameters associated with general equilibrium models. A unique feature of the model is the critical role played by inventories. While our analysis focuses exclusively on factorspecific tax credits, it can be applied to more complicated situations involving income and other business taxes and, in future work, could be incorporated into general equilibrium frameworks.

A dynamic optimization model is specified in Section II, and the forward-looking firm chooses labor, sales, and inventories to maximize discounted profits. The labor choice determines output, the sales choice determines the output price, and inventories are subject to an isoperimetric constraint so that its beginning and ending values are equal. The associated firstorder conditions and steady-state values are derived in Section III.

The DTC is then analyzed in perfect foresight models in terms of the responses of labor, sales, and inventories away from the steady-state. Section IV evaluates a simple DTC in a model where there are no costs to inventory imbalances. This section derives the first essential result of the paper -- the three sufficient conditions for fiscal foresight to distort economic activity. Perverse incentives lead to an anticipatory dip (AD) in labor demand before the tax credit policy is implemented and a compensating rebound (CR) afterwards. ${ }^{3}$ An inventory technology provides the means to shift production across periods. Decreasing returns and a non-competitive output market provide the motivation to smooth real activity across periods. All three elements

\footnotetext{
${ }^{2}$ A non-competitive output market refers to any market structure in which the firm does not take prices as given, such as monopoly, Bertrand, Cournot, and Stackelberg competition.

${ }^{3}$ Distorted behavior is symmetric to the case of a tax increase instead of a tax cut or credit. That is, a delayed tax increase on labor (e.g., a future increase in the payroll/FICA tax rate) yields an anticipatory spike in labor demand prior to implementation followed by a compensating decline after implementation.
} 
are needed to provide the firm the means and motivation to shift employment, output, and sales intertemporally and generate ADs and CRs.

Section $\mathrm{V}$ extends the model by including a cost when the inventory/sales ratio differs from its target. The key qualitative results remain robust to this extension, though the quantitative effects change.

Section VI identifies an alternative set of sufficient conditions, relating to the design of the fiscal policy itself, that yield an $\mathrm{AD}$ and $\mathrm{CR}$. Some types of taxes and tax credits feature a "rolling base." For example, job creation tax credits often are based on employment above a rolling average of recent employment (or simply last year's employment). Likewise, R\&D tax credits adopted by some U.S. states are a function of the current R\&D to sales ratio relative to its recent rolling average. The U.S. federal R\&D tax credit had a similar design until 1990. This analysis would also apply equally well to any tax with a rolling base feature, such as a tax on pollutant emissions above recent levels that could lead to a boost in production and emissions in anticipation of the tax followed by a compensating dip. We show that a rolling base, combined with storable output, also is sufficient to cause a tax or credit to cause unintended intertemporal distortions.

Section VII discusses our results relative to prior theoretical models, and Section VIII offers a brief summary. 


\section{Optimization Problem}

Cash flow in period $t$ is composed of four elements. First, revenues $\left(\mathrm{REV}_{t}\right)$ accrue to the firm from sales $\left(S_{t}\right)$ in a market where the firm may have market power $\left(P_{t}=P\left[S_{t}\right], P^{\prime}\left[S_{t}\right] \leq 0\right)$. The demand curve is linear with slope $(-\beta / 2)$ and a constant term equal to $(1+\beta)$. The linearity assumption is made for convenience; the parametric restriction as a simple device for assuring that, in the steady-state (SS), the firm faces an elastic demand curve for any positive value of $\beta$,

$$
\begin{aligned}
& \operatorname{REV}\left[\mathrm{S}_{\mathrm{t}}\right] \equiv \mathrm{P}_{\mathrm{t}} * \mathrm{~S}_{\mathrm{t}}=\alpha * \mathrm{~S}_{\mathrm{t}}-(\beta / 2) * \mathrm{~S}_{\mathrm{t}}^{2}, \\
& \alpha \equiv 1+\beta, \\
&\left|\frac{\mathrm{dS}_{\mathrm{t}}}{\mathrm{dP}_{\mathrm{t}}} \frac{\mathrm{P}_{\mathrm{t}}}{\mathrm{S}_{\mathrm{t}}}\right|_{\mathrm{SS}}=(1+2 / \beta)>1 \quad 0 \leq \beta<\infty,
\end{aligned}
$$

where we assume in equation (1c) that the steady-state value of $S_{t}$ equals one (an assumption verified in Section III).

Second, labor is the only factor of production, and production $\operatorname{cost}\left(\mathrm{COST}_{t}\right)$ is the product of an exogenous wage $(w)$ and labor input $\left(\mathrm{L}_{\mathrm{t}}\right)$,

$$
\operatorname{COST}\left[\mathrm{L}_{\mathrm{t}}\right] \equiv \mathrm{w}^{*} \mathrm{~L}_{\mathrm{t}} .
$$

Third, the firm smooths production intertemporally by adjusting the end-of-the-period inventory stock $\left(\mathrm{I}_{\mathrm{t}}\right)$. The firm has an exogenous target inventory-to-sales ratio $(\zeta)$. Deviations from this target result in the following quadratic cost,

$$
\mathrm{f}\left[\mathrm{I}_{\mathrm{t}-1}, \mathrm{~S}_{\mathrm{t}}\right] \equiv(\mu / 2) *\left(\mathrm{I}_{\mathrm{t}-1}-\zeta * \mathrm{~S}_{\mathrm{t}}\right)^{2} \quad \mu \geq 0
$$

Such a cost is standard in the inventory literature (cf., Ramey and West, 1999, equation 3.1) and represents inventory holding and stock-out costs. If $\zeta$ equals $0, f[$.$] is linear, and (\mu / 2)$ equals the cost of borrowed funds, then equation (3) would represent the carrying cost of inventory. 
Fourth, the firm receives a tax credit equal to the product of the legislated tax credit rate $\left(\tau_{t}\right)$, the wage rate, and the level of credit-qualifying employment. Because the previous period is not a fixed interval at a point in time but rather a window that moves forward in time with employment, this type of credit is known as a "rolling base" credit. The rolling base feature of these credits has important implications on the incentives from and the costs of tax credit programs. These implications are examined in Section VI below. Here we assume a rolling base $\left(\mathrm{BASE}_{\mathrm{t}}\right)$ and the tax credit received by the firm is defined as follows, ${ }^{4}$

$$
\begin{gathered}
\mathrm{g}\left[\mathrm{L}_{\mathrm{t}}, \mathrm{L}_{\mathrm{t}-1}: \tau_{\mathrm{t}}\right] \equiv \tau_{\mathrm{t}} * \mathrm{w} *\left(\mathrm{~L}_{\mathrm{t}}-\mathrm{BASE}_{\mathrm{t}}\right) \\
\operatorname{BASE}_{\mathrm{t}} \equiv \mathrm{L}_{\mathrm{t}-1}
\end{gathered}
$$

The tax credit rate is noted explicitly in equation (4a) as a conditioning variable given its central role in the subsequent analysis. An implicit assumption in the theoretical model is that the firm has positive taxable profits and/or that the credit is fully refundable (i.e., the firm does not need taxable profits to receive the credit). ${ }^{5}$

In maximizing cash flow qua profits over the planning period, the firm faces production function, inventory accumulation, and isoperimetric constraints. The production function depends only on labor, ${ }^{6}$

$$
\mathrm{Q}_{\mathrm{t}}=\mathrm{L}_{\mathrm{t}}^{(1 / \gamma)}
$$

\footnotetext{
${ }^{4}$ An alternative to a rolling base is a fixed base defined, for example, as an average of employment in a fixed interval, $\mathrm{BASE}_{\mathrm{t}} \equiv\left(\mathrm{L}_{\mathrm{s}}+\mathrm{L}_{\mathrm{s}-1}\right) / 2, \mathrm{~s}<\mathrm{t}$ with s fixed.

${ }^{5}$ This assumption could be relaxed (though at the cost of additional notation) by carrying unused tax losses forward or backward, a procedure that characterizes many tax systems.

${ }^{6}$ This formulation of the production function is consistent with a constant returns-to-scale production function with labor and a fixed factor as arguments, where the latter is normalized to one and fixed during the length of the period over which we evaluate the impact of the DTC.
} 
where $\gamma \geq 1$; when $\gamma>1$, returns to labor are decreasing. The latter property will be required for satisfying the second-order conditions and ensuring the uniqueness of the steady-state in the general model. The end-of-period inventory stock is accumulated according to the following recursive equation,

$$
I_{t}=Q_{t}-S_{t}+I_{t-1}
$$

Equation (6) will be appended to the optimization problem with a time-varying shadow price, $\theta_{\mathrm{t}}$. The final constraint concerns the inventory stock at the end of the planning period. The firm begins the planning period with an inventory stock, $\mathrm{I}_{0}$. If left unconstrained, the firm will end the planning period at time $\mathrm{T}$ with the inventory stock completely depleted, and some of its profit will be illusory. To avoid this extreme inventory drawdown that would distort profits and employment decisions, we require that $\mathrm{I}_{\mathrm{T}}=\mathrm{I}_{0}$, which, after repeated substitution with equation (6), is equivalent to the following isoperimetric constraint,

$$
\mathrm{I}_{\mathrm{T}}-\mathrm{I}_{0}=0=\sum_{\mathrm{t}=1}^{\mathrm{T}}\left(\mathrm{Q}_{\mathrm{t}}-\mathrm{S}_{\mathrm{t}}\right) .
$$

Equation (7) is a weaker constraint than the special case of assuming the firm starts with zero inventory because, in this special case, the firm might not have the possibility of allowing sales to exceed output in the early periods. This constraint will be appended to the optimization problem with a time-invariant shadow price, $\phi$. This constant shadow price of output plays a critical role in relating fiscal foresight to perverse distortions in the intertemporal allocation of labor, output, and sales and the emergence of an $\mathrm{AD}$ and $\mathrm{CR}$.

Combining the four relations defining cash flow $\left(\mathrm{CF}_{\mathrm{t}}\right)$, discounting $\mathrm{CF}_{\mathrm{t}}$ by a constant discount factor ( $\mathrm{R}^{\mathrm{t}}$ depending on a constant discount rate $\rho$ ), assuming that cash flows accrue at the end of the period, substituting $\mathrm{L}_{t}$ for $\mathrm{Q}_{\mathrm{t}}$ with equation (5), and appending the two constraints, we write the dynamic optimization problem as follows, 


$$
\begin{aligned}
& \Pi_{0}=\underset{\left\{L_{t}, S_{t}, I_{t}\right\}}{\operatorname{Max}} \sum_{t=1}^{T} R^{t}\left\{C F\left[L_{t}, S_{t}, I_{t-1}, L_{t-1}: \tau_{t}\right]+\theta_{t}\left(I_{t}-L_{t}^{(1 / \gamma)}+S_{t}-I_{t-1}\right)+\phi \sum_{t=1}^{T}\left(L_{t}^{(1 / \gamma)}-S_{t}\right)\right\} \\
& \quad R^{t} \equiv(1+\rho)^{-t} \quad \rho \geq 0 \\
& \quad C F\left[L_{t}, S_{t}, I_{t-1}, L_{t-1}: \tau_{t}\right] \equiv\left(\operatorname{REV}\left[S_{t}\right]-\operatorname{COST}\left[L_{t}\right]-f\left[I_{t-1}, S_{t}\right]+g\left[L_{t}, L_{t-1}: \tau_{t}\right]\right)
\end{aligned}
$$

We have chosen to work with a finite planning horizon to enable us to analyze the rolling tax credit in Section VI and to avoid some delicate issues with transversality conditions in infinite horizon programs (Halkin, 1974; Kamihigashi, 2001). 


\section{First Order Conditions And The Steady-State}

The firm maximizes discounted cash flows by appropriate choices of labor, sales, and the inventory stock. The latter has received little attention in the foresight literature and proves critical to the results. Given the inventory constraint (equation (7)), the latter variable is predetermined by the choices of labor and sales, and it could be eliminated from equation (8) with equation (6). We include $I_{t}$ explicitly in equation (8) to facilitate the interpretation of the first-order conditions and to define $\theta_{t}$. We begin with the perturbation of equation (8) with respect to $I_{t}$,

$$
\begin{gathered}
\mathrm{I}_{\mathrm{t}}: \quad-\mathrm{R} * \mu\left(\mathrm{I}_{\mathrm{t}}-\zeta * \mathrm{~S}_{\mathrm{t}+1}\right)+\theta_{\mathrm{t}}-\mathrm{R} * \theta_{\mathrm{t}+1}=0, \\
\rightarrow \\
\theta_{\mathrm{t}}=\sum_{\mathrm{s}=0}^{\mathrm{T}} \mathrm{R}^{\mathrm{s}+1} \mu\left(\mathrm{I}_{\mathrm{t}+\mathrm{s}}-\zeta * \mathrm{~S}_{\mathrm{t}+\mathrm{s}+1}\right) .
\end{gathered}
$$

Equation (9a) is a first-order difference equation in $\theta_{t} .{ }^{7}$ It can be solved by recursive substitution for $\theta_{\mathrm{t}+\mathrm{s}}$ and by imposing the terminal condition that $\theta_{\mathrm{T}}$ equals zero (discussed below). This solution is presented in equation (9b) and defines $\theta_{t}$ as the shadow price of adding a unit of inventory in period $t$ and keeping that unit in inventory until period $T$. If in period $t$, the inventory stock exceeds its target level $\left(\mathrm{I}_{\mathrm{t}+\mathrm{s}}-\zeta * \mathrm{~S}_{\mathrm{t}+\mathrm{s}+1}>0\right)$, an addition to inventory aggravates the imbalance, is costly to the firm, and $\theta_{t}>0$. This imbalance is monetized by $\mu$ and is discounted by R. If in period t, the inventory stock is below its target level, then the additional unit is beneficial to the firm, the incremental cost is negative, and $\theta_{t}<0$. Inventory imbalances are reduced monotonically to zero. Given the quadratic specification, inventory imbalances of either sign are penalized, and it would be unnecessarily costly for the firm to overshoot the steady-state value. In the steady-state, the inventory stock equals its target level, the inventory imbalance is zero, and $\theta_{\mathrm{t}}=0$.

\footnotetext{
${ }^{7}$ If the cash flow term defining the inventory costs (equation (3)) had also included an inventory carrying $\operatorname{cost}\left(\mathrm{c} * \mathrm{I}_{\mathrm{t}-1}\right)$, this additional cost term would have merely redefined $\theta_{\mathrm{t}}$.
} 
The key decisions made by the firm concern labor and sales. The first-order condition for labor is as follows,

$$
\begin{array}{ll}
\mathrm{L}_{\mathrm{t}}: & \mathrm{w}_{\mathrm{t}}^{\mathrm{EFF}-\mathrm{N}}+\theta_{\mathrm{t}} * \mathrm{MPL}\left[\mathrm{L}_{\mathrm{t}}\right]=\phi^{*} \operatorname{MPL}\left[\mathrm{L}_{\mathrm{t}}\right], \\
\rightarrow & \\
\mathrm{MPL}\left[\mathrm{L}_{\mathrm{t}}\right]=\mathrm{w}_{\mathrm{t}}^{\mathrm{EFF}-\mathrm{N}} /\left(\phi-\theta_{\mathrm{t}}\right) \equiv \mathrm{w}_{\mathrm{t}}^{\mathrm{EFF}-\mathrm{R}} & \mathrm{w}_{\mathrm{t}}^{\mathrm{EFF}-\mathrm{N}} \equiv \mathrm{w}^{*}\left(1-\tau_{\mathrm{t}}+\tau_{\mathrm{t}+1} * \mathrm{R}\right) \\
\rightarrow & \left.\mathrm{MPL}_{\mathrm{t}}^{\mathrm{EFF}-\mathrm{R}} \equiv \mathrm{L}_{\mathrm{t}}\right] \equiv \mathrm{L}_{\mathrm{t}}^{(1-\gamma) / \gamma)} / \gamma \\
\mathrm{L}_{\mathrm{t}}=\left(\gamma * \mathrm{w}_{\mathrm{t}}^{\mathrm{EFF}-\mathrm{R}}\right)^{(\gamma /(1-\gamma))},\left(\phi-\theta_{\mathrm{t}}\right), \\
\mathrm{Q}_{\mathrm{t}}=\left(\gamma * \mathrm{w}_{\mathrm{t}}^{\mathrm{EFF}-\mathrm{R}}\right)^{(1 /(1-\gamma))} . & (\gamma /(1-\gamma))<0
\end{array}
$$

The two terms on the left side of equation (10a) define the total cost from hiring an incremental worker (and hence producing incremental output). The first term reflects labor costs represented by the effective nominal wage rate, $\mathrm{w}_{\mathrm{t}}^{\mathrm{EFF}-\mathrm{N}}$, which is equal to the sum of the cost of hiring labor (w), minus the tax credit $\left(-\mathrm{w}^{*} \tau_{\mathrm{t}}\right)$ received in period $\mathrm{t}$ and, owing to the rolling base feature of the tax credit, plus the tax credit that will not be received in period $t+1\left(w^{*} \tau_{t+1} * R\right)$ (discussed in more detail in Section VI). Taken together, these latter two terms form the effective tax credit rate that differs markedly from the legislated tax credit rate, $\tau$. The second term is the cost of adding to an inventory imbalance. If $\theta_{t}$ is positive due to a positive inventory imbalance, incremental output from a new hire increases the imbalance and is costly to the firm. These two incremental costs equal the benefit from an additional hire, the latter represented by the term on the right side of equation (10a). This term is the constant shadow price of output, $\phi$, multiplied by the marginal product of labor.

These relations are rearranged into a more concise expression in equation (10b). Labor is chosen optimally so that its marginal product is set equal to the effective real wage rate $\left(w_{t}^{\text {EFF-R }}\right)$. This factor price equals the effective nominal wage rate $\left(w_{t}^{E F F-N}\right)$ “deflated" by the true price of output, which is its shadow price $(\phi)$ net of any cost due to an inventory imbalance 
$\left(\theta_{t}\right)$. Equation (10c) is a rearrangement of equation (10b) and relates $L_{t}$ to the production function parameter, shadow prices, and the effective real wage rate. (In the derivations below, it proves more convenient to return to the notation with the effective nominal wage rate.) Equation (10d) is the corresponding expression for $Q_{t}$. The object $\left(\phi-\theta_{t}\right)$ appearing in the numerators is always positive given the positive wage rate term in equation (10a).

The second key choice by the firm concerns sales determined by the following firstorder condition,

$$
\begin{aligned}
\mathrm{S}_{\mathrm{t}}: \quad & \left(\alpha-\beta * \mathrm{~S}_{\mathrm{t}}\right)+\mu * \zeta\left(\mathrm{I}_{\mathrm{t}-1}-\zeta * \mathrm{~S}_{\mathrm{t}}\right)+\theta_{\mathrm{t}}=\phi, \\
\rightarrow & \mathrm{S}_{\mathrm{t}}=\frac{\alpha+\mu * \zeta * \mathrm{I}_{\mathrm{t}-1}-\left(\phi-\theta_{\mathrm{t}}\right)}{\beta+\mu * \zeta^{2}} .
\end{aligned}
$$

Equation (11a) is a perturbation of equations (8) that impacts cash flow in three ways. The first term in equation (11a) is the marginal revenue, which decreases in the level of sales if the firm operates in a non-competitive output market. The second term reflects the cash flow from a change in the target and depends on the sign of the inventory imbalance. An increase in sales reduces a positive imbalance and adds to cash flow. The impact is negative when the inventory imbalance is negative. This effect disappears if the target level is zero $(\zeta=0)$. The third term is the shadow price of inventory imbalances. The shadow price's impact on an incremental sale is opposite to its impact on labor because $\mathrm{Q}_{t}$ (dependent on $\mathrm{L}_{t}$ ) and $\mathrm{S}_{\mathrm{t}}$ have opposite but numerically identical effects on the inventory stock. These three terms define the total cash flow from an incremental sale and, under profit-maximization, equal the constant shadow price of output, $\phi$. If the second and third terms are zero, then $\phi$ equals the marginal revenue product $\left(\alpha-\beta * S_{t}\right)$. Equation (11b) is a rearrangement of equation (11a) that relates $S_{t}$ to demand curve parameters, the predetermined lagged inventory stock, and shadow prices.

Lastly, perturbations of the shadow prices yield the per-period inventory accumulation constraint and the planning-period isoperimetric constraint, respectively, 


$$
\begin{array}{ll}
\theta_{\mathrm{t}}: & \mathrm{I}_{\mathrm{t}}=\mathrm{L}_{\mathrm{t}}^{(1 / \gamma)}-\mathrm{S}_{\mathrm{t}}+\mathrm{I}_{\mathrm{t}-1}, \\
\phi: & \sum_{\mathrm{t}=1}^{\mathrm{T}}\left(\mathrm{L}_{\mathrm{t}}^{(1 / \gamma)}-\mathrm{S}_{\mathrm{t}}\right)=0,
\end{array}
$$

These first-order conditions form the basis of our analysis of the steady-state and the response to a DTC. We analyze a steady-state defined by four characteristics:

1) the inventory stock equals its target value $\left(\mathrm{I}_{\mathrm{sS}}=\zeta * \mathrm{~S}_{\mathrm{sS}}\right)$,

2) tax credits are absent (hence $\left.\mathrm{w}_{\mathrm{SS}}^{\mathrm{EFF}-\mathrm{N}}=\mathrm{w}\right)$,

3) sales equals output $\left(\mathrm{S}_{\mathrm{SS}}=\mathrm{Q}_{\mathrm{SS}}\right)$,

4) the wage rate is normalized $(\mathrm{w}=(1 / \gamma) \leq 1)$.

The first characteristic implies that $\theta_{\mathrm{SS}}=0$ and, combined with the second characteristic, that labor, output, and sales given by equations (10c), (10d) and (11b), respectively, can be written as follows,

$$
\begin{aligned}
& \mathrm{L}_{\mathrm{SS}}=\left(\frac{\phi_{\mathrm{SS}}}{\gamma^{*} \mathrm{w}}\right)^{(\gamma /(\gamma-1))}, \\
& \mathrm{Q}_{\mathrm{SS}}=\left(\frac{\phi_{\mathrm{SS}}}{\gamma^{*} \mathrm{w}}\right)^{(1 /(\gamma-1))}=\left(\mathrm{L}_{\mathrm{SS}}\right)^{1 / \gamma}, \\
& \mathrm{S}_{\mathrm{SS}}=\frac{\alpha-\phi_{\mathrm{SS}}}{\beta} .
\end{aligned}
$$

The third and fourth characteristics of the steady-state, along with the constraint in equation (1b), imply the following solution for the shadow price of output, 


$$
\begin{aligned}
& \mathrm{S}_{\mathrm{SS}}-\mathrm{Q}_{\mathrm{SS}}=0, \\
& \rightarrow \\
& \mathrm{h}\left[\phi_{\mathrm{SS}}\right] \equiv \frac{\alpha-\phi_{\mathrm{SS}}}{\beta}-\left(\phi_{\mathrm{SS}}\right)^{(1 /(\gamma-1))}=0 . \quad \alpha=1+\beta
\end{aligned}
$$

This solution is unique for non-negative values of $\phi_{\mathrm{SS}}$. From equation (16), we know that $\mathrm{h}\left[\phi_{\mathrm{SS}}=0\right]=((1+\beta) / \beta)>0$. For $\forall \phi_{\mathrm{SS}}>0, \gamma>1$, and $\beta>0, \mathrm{~h}[$.$] is negatively sloped,$

$$
\mathrm{h}^{\prime}\left[\phi_{\mathrm{SS}}\right]=-(1 / \beta)-(1 /(\gamma-1))\left(\phi_{\mathrm{SS}}\right)^{((2-\gamma) /(\gamma-1))}<0 .
$$

Thus, if $\mathrm{h}\left[\phi_{\mathrm{SS}}\right]$ crosses the horizontal axis, it only occurs once. Per equation (16), $\phi_{\mathrm{SS}}=1$ is the unique solution.

This solution also satisfies the second-order conditions for a maximum. The matrix of second derivatives for the two choice variables, $\mathrm{L}$ and $\mathrm{S}$ (computed from equations (10a) and (11a), respectively, with the steady-state restrictions), is as follows, ${ }^{8}$

$$
\left[\begin{array}{lr}
\left((1-\gamma) / \gamma^{2}\right) * L^{(1-2 \gamma) / \gamma)} & 0 \\
0 & -\beta
\end{array}\right],
$$

which is negative definite for $\gamma>1$ and $\beta>0$.

With this value for the shadow price of output, $\mathrm{S}_{\mathrm{SS}}=\mathrm{Q}_{\mathrm{SS}}=\mathrm{L}_{\mathrm{SS}}=1$. The usefulness of these results is that the optimal choices of sales, output, and labor in the initial steady-state are each 1 . Therefore, the effects of introducing a DTC can be easily computed as a deviation from unity.

\footnotetext{
${ }^{8}$ The first-order condition for $I_{t}$ vanishes in the steady-state.
} 


\section{Intertemporal Distortions From A Delayed Tax Credit (DTC): Sufficient Conditions In The Economic Environment}

The next three sections study the firm's responses to the introduction of a DTC and the sufficient conditions for fiscal foresight to distort economic decisions. To highlight the channels of influence, Section IV examines a special case of the model in which deviations from the target inventory are costless and the rolling base is eliminated. The model presented in this section captures our essential results for the sources of perverse real distortions. Section V extends the model by including costly inventory deviations and shows that the qualitative results are robust. Section VI analyzes the role of a rolling credit base in generating a second set of conditions leading to perverse effects.

We divide the timeline for a firm facing a DTC into two intervals,

BEFORE: The months between the adoption date and the implementation date; that is, the implementation period. The beginning of the BEFORE interval is defined by the adoption date for convenience and, without loss in generality, could be extended backwards to include the preview lag discussed at the beginning of this paper.

AFTER: The months on and after the implementation date.

The adoption and implementation dates define these two DTC intervals that may exhibit different real responses. When the implementation date occurs after the adoption date, forwardlooking firms anticipate the forthcoming decline in the effective wage. With this fiscal foresight, they may have an incentive to initially decrease employment and output during the implementation period and then compensate for this decrease by raising employment and output sharply at the implementation date. There may be related effects on sales. We refer to this potential negative effect on employment as an Anticipatory Dip (AD) and the subsequent offsetting positive effect as a Compensating Rebound (CR). Each is potentially driven by fiscal foresight. However, a DTC policy may not translate into impactful incentives and real actions. It is the purpose of the remaining part of this paper to uncover the sufficient conditions under which an AD and a CR will occur as a result of a DTC.

We assume that the firm begins in the steady-state with no tax credit. At the beginning of the planning period, policymakers adopt a permanent tax credit with an implementation date in the future. This situation describes a DTC and leads to some very interesting dynamic behavior 
for employment, output, and sales. Two assumptions adopted in this section -- costs associated with deviations from the target inventory/sales ratio are absent $\left(\mu=0 \rightarrow \theta_{\mathrm{t}}=0 \forall \mathrm{t}\right)$ and the rolling base is replaced $\left(\mathrm{BASE}_{\mathrm{t}}=\right.$ constant $\left.\forall \mathrm{t}\right)$ - will be relaxed in the subsequent two sections.

The first-order conditions for labor and sales are as follows,

$$
\begin{array}{ll}
\mathrm{L}_{\mathrm{t}}=\left(\frac{\phi}{\left.\gamma^{*} \mathrm{w}_{\mathrm{t}}^{\mathrm{EFF}-\mathrm{N}}\right)^{(\gamma /(\gamma-1))}} \quad \mathrm{w}_{\mathrm{t}}^{\mathrm{EFF}-\mathrm{N}} \equiv \mathrm{w}\right. & \mathrm{t} \in\{\mathrm{BEFORE}\}, \\
\mathrm{L}_{\mathrm{t}}=\left(\frac{\phi}{\gamma^{*} \mathrm{w}_{\mathrm{t}}^{\mathrm{EFF}-\mathrm{N}}}\right)^{(\gamma /(\gamma-1))} \quad \mathrm{w}_{\mathrm{t}}^{\mathrm{EFF}-\mathrm{N}} \equiv \mathrm{w} *\left(1-\tau_{\mathrm{t}}\right) & \mathrm{t} \in\{\text { AFTER }\}, \\
\mathrm{S}_{\mathrm{t}}=\frac{\alpha-\phi}{\beta} & \mathrm{t} \in\{\text { BEFORE, AFTER }\}, \\
\mathrm{Q}_{\mathrm{t}}=\left(\frac{\phi}{\gamma^{*} \mathrm{w}_{\mathrm{t}}^{\mathrm{EFF}-\mathrm{N}}}\right)^{(1 /(\gamma-1))}=\left(\mathrm{L}_{\mathrm{t}}\right)^{(1 / \gamma)} & \mathrm{t} \in\{\text { BEFORE, AFTER }\} .
\end{array}
$$

The introduction of the DTC can be understood by considering several discrete steps. First, it lowers $\mathrm{w}_{\mathrm{t}}^{\mathrm{EFF}-\mathrm{N}}$ in the AFTER interval. Thus, $\mathrm{L}_{\mathrm{t}}$ rises at the time of the implementation date and stays permanently higher. These initial hiring and production plans lead to an imbalance with $S_{t}$, which, for the moment, remains fixed. An appropriate change in the shadow price of output restores the balance over the planning period. In equations (19), the decline in $\phi$ (below its initial steady state value of 1 ) has three effects:

raising $\mathrm{S}_{\mathrm{t}}$ uniformly in both intervals,

- lowering $\mathrm{L}_{\mathrm{t}}$ and $\mathrm{Q}_{\mathrm{t}}$ in the BEFORE interval,

- also lowering $\mathrm{L}_{t}$ and $\mathrm{Q}_{\mathrm{t}}$ in the AFTER interval; however, this decrease is more than offset by the stimulus from the lower effective nominal wage rate if the elasticity of $\phi_{\mathrm{SS}}$ with respect to $\mathrm{w}_{\mathrm{SS}}^{\mathrm{EFF}-\mathrm{N}}\left(\varepsilon\left[\phi_{\mathrm{SS}}, \mathrm{w}_{\mathrm{SS}}^{\mathrm{EFF}-\mathrm{N}}\right]\right)$ is less than one. 
To evaluate this elasticity, we rewrite the steady-state relation $\mathrm{h}\left[\phi_{\mathrm{SS}}\right]$ (equation 16) in terms of $\mathrm{w}_{\mathrm{SS}}^{\mathrm{EF}-\mathrm{N}}$ (which does not generally appear in $\mathrm{h}\left[\phi_{\mathrm{SS}}\right]$ because of the normalization, $\mathrm{w}=(1 / \gamma)<1$ ),

$$
\mathrm{h}\left[\phi_{\mathrm{SS}}\right]=\frac{\alpha-\phi_{\mathrm{SS}}\left[\mathrm{w}_{\mathrm{SS}}^{\mathrm{EFF}-\mathrm{N}}\right]}{\beta}-\left(\phi_{\mathrm{SS}}\left[\mathrm{w}_{\mathrm{SS}}^{\mathrm{EFF}-\mathrm{N}}\right] /\left(\gamma * \mathrm{w}_{\mathrm{SS}}^{\mathrm{EFF}-\mathrm{N}}\right)\right)^{(1 /(\gamma-1))} \equiv \chi\left[\mathrm{w}_{\mathrm{SS}}^{\mathrm{EFF}-\mathrm{N}}\right] .
$$

In any steady-state, $\mathrm{Q}_{\mathrm{SS}}=\mathrm{S}_{\mathrm{SS}}$ and hence $\chi^{\prime}\left[\mathrm{w}_{\mathrm{SS}}^{\mathrm{EFF}-\mathrm{N}}\right]=0$ through an adjustment in $\phi$ to the change in $\mathrm{w}_{\mathrm{SS}}^{\mathrm{EF}-\mathrm{N}}$. Differentiating $\chi\left[\mathrm{w}_{\mathrm{SS}}^{\mathrm{EFF}}\right]$ with respect to $\mathrm{w}_{\mathrm{SS}}^{\mathrm{EFF}-\mathrm{N}}$, setting the derivative equal to zero, and evaluating this derivative at the original steady-state, we obtain

$$
\varepsilon\left[\phi_{\mathrm{SS}}, \mathrm{w}_{\mathrm{SS}}^{\mathrm{EFF}}\right]=(\beta /(\beta+\gamma-1))<1,
$$

provided $\beta>0$ and $\gamma>1$. This elasticity is a crucial object in analyzing fiscal foresight and identifying two factors - a non-competitive output market $(\beta>0)$ and diminishing returns $(\gamma>1)$ - necessary for the emergence of an $\mathrm{AD}$ and $\mathrm{CR} .{ }^{9}$

The above analysis generates an AD due to fiscal foresight. Even though the effective nominal wage rate in the BEFORE interval does not change, the effective real wage rate rises and, consequently, employment in that interval falls relative to its prior steady-state value. This change represents a shift in production from high-cost to low-cost periods as the firm, foreseeing the future changes in the effective real wage rates, adopts an intertemporal production plan that minimizes production costs and satisfies endogenous sales and fixed inventory constraints.

The AD directly leads to a CR. The level of sales following from the DTC is determined by a lower steady-state value of the shadow price of output, and thus sales rise in both intervals. When an AD occurs in the BEFORE interval, output (and employment) during the AFTER

\footnotetext{
${ }^{9}$ Our Anticipatory Dip differs from an Ashenfelter Dip (Ashenfelter, 1978; Heckman and Smith, 1999). While both Dips involve transitory declines of employment and earnings, respectively, prior to the implementation of a policy, the channels differ. The Ashenfelter Dip is a selection phenomenon driven by low opportunity costs; an Anticipatory Dip is driven by intertemporal tradeoffs.
} 
interval must be larger than its steady-state value to compensate for the lost output and to meet the inventory constraint. This extra employment is the CR.

An inventory technology, decreasing returns to labor, and a non-competitive output market are required elements for the $\mathrm{AD}$ and $\mathrm{CR}$ to emerge. If an inventory technology is absent, then $Q_{t}$ must equal $S_{t}$ in each period, and the firm no longer has a separate sales decision. ${ }^{10}$ In this case, the inability to change inventory across periods prevents the firm from taking advantage of the differential production costs due to the delayed implementation of the tax credit program. There are no interrelations among anticipated future tax incentives and current employment and output decisions. While employment and output in the AFTER period will rise as a result of the tax credit, the dynamic optimization problem becomes a sequence of static problems, and there are no perverse impacts in the BEFORE interval.

Decreasing returns to labor are also required for the AD and CR. Per equations (19), a tax credit has two opposing effects on $\mathrm{L}_{t}$ in the AFTER interval - a direct stimulus from the tax credit $\left(w_{S S}^{\mathrm{EFF}-\mathrm{N}}\right)$ and an indirect counter-stimulus from the lower shadow price of output $\left(\phi_{\mathrm{SS}}\right)$. As shown in equation (20b), the formula for $\varepsilon\left[\phi_{\mathrm{SS}}, \mathrm{w}_{\mathrm{SS}}^{\mathrm{EFF}-\mathrm{N}}\right]<1$ when $\gamma>1$, the direct effect dominates, $\mathrm{w}_{\mathrm{SS}}^{\mathrm{EFF}-\mathrm{R}}$ falls, and the tax credit imparts a net positive stimulus in the AFTER interval. Additionally, the rise in $\phi_{\mathrm{SS}}$ affects real decisions in the BEFORE interval, employment and output fall, and an $\mathrm{AD}$ emerges.

As an aside, the knife-edge case of a linear production technology $(\gamma=1)$ deserves special consideration. If the production technology is linear and returns are constant, then the tax credit does not impact real behavior in the AFTER interval, and thus there cannot be any subsequent effect in the BEFORE interval and no AD. In this case, $\gamma=1, \varepsilon\left[\phi_{\mathrm{SS}}, \mathrm{w}_{\mathrm{SS}}^{\mathrm{EFF}-\mathrm{N}}\right]=1$, and the following scenario unfolds for the firm facing a linear production technology:

\footnotetext{
${ }^{10}$ If an inventory technology is not available to the firm, the inventory accumulation constraint $\left(I_{t}=Q_{t}-S_{t}+I_{t-1}\right)$ would be removed from the optimization problem (equation (8a)) and $S_{t}$ would be replaced by $Q_{t}$ for all $t$.
} 
1. The tax credit lowers $\mathrm{w}_{\mathrm{SS}}^{\mathrm{EF}-\mathrm{N}}$ in the AFTER interval,

2. Provisionally, the firm increases output in the AFTER interval,

3. Looking ahead, the firm realizes that it will have to decrease $\phi_{\mathrm{SS}}$ to sell the provisional increase in output,

4. The decrease in $\phi_{\mathrm{SS}}$ raises the effective real wage rate,

$$
\mathrm{w}_{\mathrm{SS}}^{\mathrm{EFF}-\mathrm{R}} \equiv \mathrm{w}_{\mathrm{SS}}^{\mathrm{EFF}-\mathrm{N}} / \phi_{\mathrm{SS}},
$$

5. As shown by equations (20b) and (10b), $\varepsilon\left[\phi_{\mathrm{SS}}, \mathrm{w}_{\mathrm{SS}}^{\mathrm{EFF}-\mathrm{N}}\right]=1, \mathrm{w}_{\mathrm{SS}}^{\mathrm{EFF}-\mathrm{R}}$ does not change, and thus there is no incentive for the firm to increase output in the AFTER interval.

6. The provisional increase in output (point 2) is reversed.

Since output has not changed in the AFTER interval, there is no change in $\phi_{\mathrm{SS}}$, and hence no AD or CR.

The third necessary condition is a non-competitive output market. If the firm faces a perfectly elastic demand curve, then production in either the BEFORE or AFTER interval could be sold without the penalty from declining marginal revenues. In this case, the dynamic elements in the optimization problem disappear, and the dynamic optimization problem again becomes a sequence of static problems. Employment, output, and sales will rise, but only in the AFTER interval. Movements in $\phi$ were critical for the increases in the AFTER interval to affect real activity in the BEFORE interval. When the demand curve is perfectly elastic, this channel is frozen because $\phi$ is fixed by the exogenous price of output. (This result is also evident in the formula for $\varepsilon\left[\phi_{\mathrm{SS}}, \mathrm{w}_{\mathrm{SS}}^{\mathrm{EFF}-\mathrm{N}}\right]$ in equation (20b) -- when $\beta=0, \varepsilon\left[\phi_{\mathrm{SS}}, \mathrm{w}_{\mathrm{SS}}^{\mathrm{EFF}-\mathrm{N}}\right]=0$.) Real variables cannot change in the BEFORE interval, and an AD does not exist.

In sum, an inventory technology provides the means to shift production across periods. Decreasing returns and a non-competitive output market provide the motivation to smooth real activity across periods. All three elements are needed to provide the firm the means and motivation to shift employment, output, and sales intertemporally and generate ADs and CRs. 


\section{Intertemporal Distortions From A Delayed Tax Credit (DTC): Introducing Inventory Costs}

The model is now extended by introducing a cost associated with inventory imbalances. The first-order conditions for the general model are modified by including terms containing the cost of inventory imbalances ( $\mu$ interacted with the deviation from the inventory/sales target, $\zeta$; cf. equation (3)) and the shadow price of adding to inventory imbalances ( $\theta_{t}$ defined in equation (9)),

$$
\begin{array}{ll}
\mathrm{L}_{\mathrm{t}}=\left(\frac{\phi-\theta_{\mathrm{t}}}{\gamma^{*} \mathrm{w}_{\mathrm{t}}^{\mathrm{EF}-\mathrm{N}}}\right)^{(\gamma /(\gamma-1))} \mathrm{w}_{\mathrm{t}}^{\mathrm{EFF}-\mathrm{N}} \equiv \mathrm{w} & \mathrm{t} \in\{\text { BEFORE }\}, \\
\mathrm{L}_{\mathrm{t}}=\left(\frac{\phi-\theta_{\mathrm{t}}}{\gamma^{*} \mathrm{w}_{\mathrm{t}}^{\mathrm{EFF}-\mathrm{N}}}\right)^{(\gamma /(\gamma-1))} \mathrm{w}_{\mathrm{t}}^{\mathrm{EFF}-\mathrm{N}} \equiv \mathrm{w} *\left(1-\tau_{\mathrm{t}}\right) & \mathrm{t} \in\{\text { AFTER }\}, \\
\mathrm{S}_{\mathrm{t}}=\frac{\alpha+\mu * \zeta * \mathrm{I}_{\mathrm{t}-1}+\theta_{\mathrm{t}}-\phi_{\mathrm{SS}}}{\beta+\mu * \zeta^{2}} & \mathrm{t} \in\{\text { BEFORE,AFTER }\}, \\
\mathrm{Q}_{\mathrm{t}}=\left(\frac{\phi-\theta_{\mathrm{t}}}{\delta^{*} \mathrm{w}_{\mathrm{t}}^{\mathrm{EFF}-\mathrm{N}}}\right)^{(1 /(\gamma-1))}=\left(\mathrm{L}_{\mathrm{t}}\right)^{(1 / \gamma)} & \mathrm{t} \in\{\text { BEFORE,AFTER }\},
\end{array}
$$

The introduction of costly inventory imbalances modifies the quantitative but not the qualitative effects of the DTC analyzed above. As discussed in prior sections, we start with $S_{t}$ and $\phi$ held at their initial steady-state levels and then, initially, allow employment to increase in the AFTER interval in response to the tax stimulus and decrease in the BEFORE interval due to the decline in $\phi$. The BEFORE response in employment results in an inventory drawdown, $\theta_{\mathrm{t}}<0$ (per equation (9b)), and incremental employment in all periods becomes more valuable by reducing the inventory imbalance. Consequently, an unambiguous implication of the general model is that inventory costs lead to a smaller fall in employment in the BEFORE interval. Nonetheless, the net effect remains negative. 
The change in employment in the AFTER interval is subject to two contrasting effects. Since the inventory drawdown in the BEFORE period is lower, the need to replenish inventory and employment is lower than under the scenario in Section IV. However, there is an added incentive to hire labor and produce output to eliminate the costly inventory imbalance; this channel spurs employment. Relative to the prior scenario, the net effect of the introduction of inventory costs on employment is ambiguous in the AFTER interval. Nonetheless, the net effect remains positive.

Inventory and sales respond differently in subsequent periods relative to the scenario in Section IV. In the face of a negative inventory imbalance, an incremental sale aggravates the imbalance, is less valuable in this more general model, and $\theta_{t}<0$. The inventory imbalance is largest in the BEFORE interval and diminishes over time. This decrease results in an increase in $\theta_{t}$ that stimulates sales over time. Rather than being constant over the planning period, sales in this more general model rise over time. As previously noted, $\phi$ adjusts so that the inventory imbalance is eliminated by the end of the planning period, at which time $\theta_{\mathrm{T}}=0$.

This section has shown that the introduction of costly inventory imbalances alters the quantitative but not the qualitative implications of the model. 


\section{Intertemporal Distortions From A Delayed Tax Credit (DTC): Sufficient Conditions In The Fiscal Policy Design}

We now consider a second set of sufficient conditions that yield an AD and CR. To highlight the role of the legislative restrictions as a unique source of perverse distortions, we begin by assuming the demand curve is perfectly elastic $(\beta=0)$; per the analyses in Sections IV and V, this assumption eliminates any perverse distortions in a model with fiscal foresight. As discussed in Section I (near equation (4)), the enabling legislation for some fiscal policies creates a "rolling base" to determine the amount of employment, research and development spending, and other items eligible for tax incentives. The intertemporal distortions and qualitative effects on employment and output are identical to those documented in Sections IV and V, though the underlying restrictions driving these intertemporal distortions differ sharply. With a rolling base, the effective nominal wage rate (equation (10b)) is impacted differently in the BEFORE interval, the AFTER interval (which now excludes the terminal period, T), and the terminal period,

$$
\begin{aligned}
& \mathrm{L}_{\mathrm{t}}=\left(\frac{\phi-\theta_{\mathrm{t}}}{\gamma * \mathrm{w}_{\mathrm{t}}^{\mathrm{EFF}-\mathrm{N}}}\right)^{(\gamma /(\gamma-1))} \quad \mathrm{w}_{\mathrm{t}}^{\mathrm{EFF}-\mathrm{N}} \equiv \mathrm{w} *\left(1-0+\tau_{\mathrm{t}+1} * \mathrm{R}\right) \quad \mathrm{t} \in\{\mathrm{BEFORE}\}, \\
& \mathrm{L}_{\mathrm{t}}=\left(\frac{\phi-\theta_{\mathrm{t}}}{\gamma^{*} \mathrm{w}_{\mathrm{t}}^{\mathrm{EF}-\mathrm{N}}}\right)^{(\gamma /(\gamma-1))} \quad \mathrm{w}_{\mathrm{t}}^{\mathrm{EFF}-\mathrm{N}}=\mathrm{w} *\left(1-\tau_{\mathrm{t}}+\tau_{\mathrm{t}+1} * \mathrm{R}\right) \quad \mathrm{t} \in\{\text { AFTER }\}, \\
& \equiv \mathrm{W} *(1-\tau *(\rho /(1+\rho))) \quad \mathrm{t} \in\{\operatorname{AFTER}\} \\
& \mathrm{L}_{\mathrm{t}}=\left(\frac{\phi-\theta_{\mathrm{t}}}{\gamma^{*} \mathrm{w}_{\mathrm{t}}^{\mathrm{EFF}-\mathrm{N}}}\right)^{(\gamma /(\gamma-1))} \quad \mathrm{w}_{\mathrm{t}}^{\mathrm{EFF}-\mathrm{N}} \equiv \mathrm{w} *\left(1-\tau_{\mathrm{t}}+0\right) \quad \mathrm{t}=\mathrm{T}, \\
& \mathrm{S}_{\mathrm{t}}=\mathrm{Q}_{\mathrm{t}} \quad \mathrm{t} \in\{\text { BEFORE, AFTER }\}, \\
& \mathrm{Q}_{\mathrm{t}}=\left(\frac{\phi-\theta_{\mathrm{t}}}{\gamma^{*} \mathrm{w}_{\mathrm{t}}^{\mathrm{EFF}-\mathrm{N}}}\right)^{(1 /(\gamma-1))}=\left(\mathrm{L}_{\mathrm{t}}\right)^{(1 / \gamma)} \quad \mathrm{t} \in\{\text { BEFORE, AFTER }\},
\end{aligned}
$$

Somewhat paradoxically, the introduction of the DTC cum rolling base raises the effective wage rate in the BEFORE interval. With a delayed tax credit, the firm is not eligible to 
receive the tax credit in the BEFORE interval, and hence obtains no benefits. However, any hiring in the BEFORE interval raises the employment base above which subsequent employment must rise to qualify for the credit. Hence, employment in the BEFORE interval lowers the value of the credit in future periods. Owing to fiscal foresight, the firm internalizes this cost when choosing employment in the BEFORE interval, and an AD occures. This negative effect on profitability is measured in equation (22a) by the product of the wage rate, the tax credit, and a discount factor.

As in Sections IV and V, the DTC lowers the effective nominal wage rate in the AFTER interval. However, per equation (22b), the quantitative impact is dramatically altered by the rolling base feature of the tax credit under which eligible incremental employment receives a tax credit today but at the expense of eliminating the tax credit on incremental employment tomorrow. This latter cost is discounted and, as the discount rate declines, the overall stimulus from the tax credit falls. If we assume that the tax credit and discount rates are constant, ${ }^{11}$ then their joint effect on $\mathrm{w}_{t}^{\mathrm{EFF}-\mathrm{N}}$ is represented in equation $\left(22 \mathrm{~b}^{\prime}\right)$ by $(\tau(\rho /(1+\rho)))$. Since the discount rate is generally a small number, the rolling base feature drives a large wedge between the legislated and effective tax credits during the AFTER interval. Assuming an expected longrun nominal return on equity of $10 \%$ and an expected long-run inflation rate of $3 \%, \rho$ is $7 \%$, and $(\rho /(1+\rho)) \approx 0.065$. Hence, during the AFTER interval, the effective tax credit rate is only $6.5 \%$ of the legislated credit rate, a reduction by approximately a factor of 15 .

The dampening effect of the rolling base on the value of the tax credit in periods 0 to $\mathrm{T}-1$ does not extend to the terminal period. At the end of the planning horizon, the dampening effect is absent because current employment no longer affects the rolling base and the value of future tax credits. Equation (22c) shows that, in period T, the effective nominal wage rate is lowered by the statutory credit rate.

The assumptions of a competitive output market and costly deviations of the inventory from its target imply that, in every period, sales equal output (equation (22d)). Since output fell

\footnotetext{
${ }^{11}$ If the tax credit is allowed to vary over time, equation (23) can be written in the following more general form: $\mathrm{w}_{\mathrm{t}}^{\text {EFF-N }} \equiv \mathrm{w} *\left(1-\tau_{\mathrm{t}}\left[\left(\rho+\mathrm{g}_{\mathrm{t}+1}^{\tau}\right) /(1+\rho)\right]\right)$, where $\mathrm{g}_{\mathrm{t}+1}^{\tau} \equiv\left(\tau_{\mathrm{t}+1} / \tau_{\mathrm{t}}\right)-1.0$.
} 
in the BEFORE interval and sales have not changed, an CR has to emerge in the AFTER interval to rebalance the inventory stock.

In sum, the rolling base, along with storable output, is a second set of required restrictions for fiscal foresight to generate perverse intertemporal distortions.

While the rolling base affects the pattern of incentives over the planning horizon, it does not affect their present value. Consider a situation where the statutory rate of the tax credit of $\$ \tau$ is offered only in the first period for an incremental hire. Since cash flows accrue at the end of the period, the present value is $\$ \tau /(1+\rho)$. This figure should be contrasted with the cumulative incentive of $\$ \tau(\rho /(1+\rho))$ for T-1 periods and then $\$ \tau$ in period T. The present value of this stream of incentives associated with the rolling base $\left(\mathrm{PV}_{\mathrm{RB}}\right)$ is computed using an annuity formula as follows,

$$
\begin{aligned}
\mathrm{PV}_{\mathrm{RB}} & =\sum_{\mathrm{t}=1}^{\mathrm{T}-1}(1+\rho)^{-\mathrm{t}} \$ \tau(\rho /(1+\rho))+(1+\rho)^{-\mathrm{T}} \$ \tau \\
& =\$ \tau(\rho /(1+\rho)) \sum_{\mathrm{t}=1}^{\mathrm{T}-1}(1+\rho)^{-\mathrm{t}}+(1+\rho)^{-\mathrm{T}} \$ \tau \\
& =\$ \tau(\rho /(1+\rho))(1 / \rho)\left[1-(1+\rho)^{-(\mathrm{T}-1)}\right]+(1+\rho)^{-\mathrm{T}} \$ \tau \\
& =\$ \tau /(1+\rho)
\end{aligned}
$$

Equation (23) establishes the equivalence between the present value of tax incentives subject to a rolling base and the present value of the statutory tax incentive taken in the first period at the statutory rate. ${ }^{12}$ Though a rolling base greatly reduces the present value of a tax credit relative to the present value of the same credit with a fixed base, (), it does not reduce $\mathrm{PV}_{\mathrm{RB}}$ to zero. Rather, the present value of a credit with a rolling base is reduced to the present value of a onetime credit. Even when $\rho=0, \mathrm{PV}_{\mathrm{RB}}$ remains positive. To our knowledge, these results have not been recognized previously in the literature, which has instead focused on the dampening effect

${ }^{12}$ This result holds even if the firm's planning horizon is infinitely long $(\mathrm{T} \rightarrow \infty)$ In this case, the first line of equation (23) is written as $\mathrm{PV}_{\mathrm{RB}, \infty}=\lim _{\mathrm{T} \rightarrow \infty} \sum_{\mathrm{t}=1}^{\mathrm{T}-1}(1+\rho)^{-\mathrm{t}} \$ \tau(\rho /(1+\rho))+\lim _{\mathrm{T} \rightarrow \infty}(1+\rho)^{-\mathrm{T}} \$ \tau=(\$ \tau(\rho /(1+\rho)))(1 / \rho)+0=\$ \tau /(1+\rho)$. 
of the rolling base and its sensitivity to the discount rate (Eisner, Albert, and Sullivan, 1984; Altshuler, 1988; Hall, 1993, 2021; Bloom, Schankerman, and Van Reenen, 2013). 


\section{Discussion}

The literature examining the empirical importance of fiscal foresight (listed in Section I) has far outpaced the number of theoretical studies giving explicit attention to decision margins. Six models are reviewed briefly here. Each contains forward-looking agents constrained by one of two adjustment frictions. In all six models, anticipated tax policies affect real activity during the implementation period, though in the first four cases the effects are in the direction intended by policymakers. This result is diametrically opposed to the perverse effects found in the current paper.

The first two models are those of Abel (1982) and Auerbach (1989). These partial equilibrium models are closest to the one developed in the current study. Their models also focus on one factor of production but, in their cases, it is capital, an assumption that resonates with their reliance on convex adjustment costs as the key friction. While these modeling assumptions are appropriate in some circumstances, there are other situations where non-convex adjustment costs are the more relevant friction and labor taxation is the policy under consideration. ${ }^{13}$ Convex adjustment costs force firms to smooth production across intervals and, in sharp contrast to the $\mathrm{AD}$, increase capital accumulation prior to the implementation date. Auerbach's model utilizes the Jorgensonian user cost and a partial adjustment framework and, if adjustment costs are absent, no distorting behavior emerges (Auerbach, p. 950). In Abel's q model, anticipated tax policy also increases capital accumulation during the implementation period. Moreover, on the implementation date, there is an additional increase in capital accumulation. His analysis "...makes it clear that an intertemporal substitution explanation must be more sophisticated than simply buying capital when it is cheap..." (Abel, p. 367).

The next two are the general equilibrium models of Judd (1985) and Leeper, Walker, and Yang (2013), which introduce smoothing through household behavior in response to future tax changes. Judd solves his model analytically using Laplace transforms. It is similar to the models in Abel, Auerbach, and the current paper owing to its theoretical structure and its focus on business taxes. Leeper, Walker, and Yang (2013, Section 2) focus on household taxes, solve a

\footnotetext{
${ }^{13}$ For example, the value of business economic development incentives offered by states is titled toward labor. In 2015, the percentages across labor, property, and tangible and intangible capital are 50\%, 27\%, and 23\%, respectively (Bartik, 2017, Table 29).
} 
second-order linear difference equation, and use simulations of VARMA models to quantify the effects of fiscal foresight. ${ }^{14}$ As with the Auerbach and Abel papers, these two papers also find that capital accumulation rises today in anticipation of a tax decrease tomorrow.

Lastly, two other general equilibrium models rely on household behavior to generate perverse responses to tax changes. Yang (2005) develops an RBC model with 24 calibrated parameters and 6 shocks to study the effects of a future increase in the rate of labor income taxation. As a result, there is a substitution of current for future labor (as households take advantage of the temporarily high returns to labor) and a rise in output in the pre-implementation period that is reversed once the higher tax rate becomes effective. Mertens and Ravn (2011) study a complicated DSGE model that depends on 12 calibrated and 12 estimated parameters, 4 of which are autoregressive parameters. In their benchmark model, an anticipated cut in labor taxes affects current output through two channels. Similar to the analysis of Yang (2005), a substitution effect lowers current labor supply. Additionally, and unique to the Mertens and Ravn (2011) model, the future tax cut reduces Harberger triangles (as distortionary income taxes are replaced by non-distortionary lump-sum taxes), increases wealth, lowers labor supply, and hence lowers output during the pre-implementation period.

General equilibrium models can be useful for analyzing aggregate fiscal policies likely to be salient to a large number of economic actors but are less relevant for evaluating more targeted business incentives. For example, state or local corporate tax incentives such as JCTCs seem unlikely to be salient to most households and hence unlikely to influence households' consumption behavior due to expectations of future tax policy. The partial equilibrium optimizing model developed in this paper emphasizes inventory and pricing decisions, does not rely on adjustment costs or incidental parameters, and illustrates that fiscal foresight may result in perverse intertemporal distortions.

\footnotetext{
${ }^{14}$ The Leeper, Walker, and Yang (2013) simulation model, as well as that of Yang (2005) discussed in the next paragraph, depends on a specific timing assumption -- that current investment has no effect on current output; relaxing this assumption may have significant effects on the model dynamics.
} 


\section{Summary}

The path from fiscal foresight to perverse real distortions in a choice theoretic model has been surprisingly long. In our partial equilibrium model, we have identified two alternative sets of sufficient conditions at least one of which must hold for fiscal foresight to generate perverse distorting behavior. The first set involves the economic environment, and the three required restrictions are storable output, diminishing returns, and a non-competitive output market. An inventory technology provides the means to shift production across periods. Decreasing returns and a non-competitive output market provide the motivation to smooth real activity before and after the implementation date. All three elements are required to provide firms the means and motivation to shift employment, output, and sales intertemporally and generate perverse firm behavior. The other set of conditions relates to legislative details. A rolling base, combined with storable output, raises the effective wage rate before policy implementation and also generates perverse intertemporal tradeoffs. We found that at least one of the two sets of conditions must hold for fiscal foresight of an anticipated tax policy to lead to anticipatory dips (AD) and compensating rebounds (CR). These conditions suggest that the estimated impacts of fiscal policies may be sensitive to underlying economic or legislative characteristics and that policies targeted to specific firms or industries with unique characteristics may not be generalizable. 


\section{References}

Abel, Andrew B. "Dynamic Effects of Permanent and Temporary Tax Policies in a $\mathrm{q}$ Model of Investment." Journal of Monetary Economics 9 (May 1982), 353-374.

Altshuler, Rosanne. "A Dynamic Analysis of the Research and Experimentation Credit." National Tax Journal 41 (December 1988), 453-466.

Ashenfelter, Orley. "Estimating the Effect of Training Programs on Earnings." Review of Economics and Statistics 60 (1978), 47-57.

Auerbach, Alan J. "Tax Reform and Adjustment Costs: The Impact on Investment and Market Value.” International Economic Review 30 (November 1989), 939-962.

Auerbach, Alan J. and Gale, William. "Activist Fiscal Policy to Stabilize Economic Activity." In Financial Stability and Macroeconomic Policy, Federal Reserve Bank of Kansas City. (2009), 327-374.

Bartik, Timothy J., "A New Panel Database on Business Incentives for Economic Development Offered by State and Local Governments in the United States," Upjohn Institute for Employment Research (January 1, 2017).

Blanchard, Olivier, and Perotti, Roberto. "An Empirical Characterization of the Dynamic Effects of Changes in Government Spending and Taxes on Output." Quarterly Journal of Economics 117 (2002), 1329-1368.

Bloom, Nicholas, Schankerman, Mark, and Van Reenen, John, "Identifying Technology Spillovers And Product Market Rivalry,” Econometrica 81/4 (July 2013), 1347-1393.

Caggiano, Giovanni Castelnuovo, Efrem, Colombo, Valentina, and Nodari, Gabriela, "Estimating Fiscal Multipliers: News from a Non-Linear World," The Economic Journal (May 2015), 746-776.

Chirinko, Robert S. and Wilson, Daniel J., "Job Creation Tax Credits, Fiscal Foresight, And Job Growth: Evidence from U.S. States" (with Daniel J. Wilson), Federal Reserve Bank of San Francisco (June 2022).

Eisner, Robert, Albert, Steven H., and Sullivan, Martin A., "The New Incremental Tax Credit For R\&D: Incentive Or Disincentive?" National Tax Journal 37 (June 1984), 171-183.

Halkin, Hubert, "Necessary Conditions for Optimal Control Problems with Infinite Horizons," Econometrica 42/2 (March 1974), 267-272. 
Hall, Bronwyn H., "R\&D Tax Policy During The 1980s: Success Or Failure?” Tax Policy and the Economy 7 (1993), 1-36. Reprinted in Albert N. Link (ed.), The Economics of Innovation Policy (Cheltenham, UK: Edward Elgar, 2007).

Hall, Bronwyn, H., "Tax Policy for Innovation," in Austan Goolsbee and Benjamin Jones (eds.), Innovation and Public Policy (Chicago and London: The University of Chicago Press (for the NBER), 2021).

Heckman, James J., and Smith, Jeffrey A. "The Pre-Programme Earnings Dip and the Determinants of Participation in a Social Programme. Implications for Simple Programme Evaluation Strategies.” Economic Journal 109 (July 1999), 313-348.

Judd, Kenneth L., "Short-Run Analysis of Fiscal Policy in a Simple Perfect Foresight Model," Journal of Political Economy 93/2 (1985), 298-319.

Kamihigashi, Takashi, "Necessity Of Transversality Conditions For Infinite Horizon Problems," Econometrica 69/4 (July 2001), 995-1012.

Kriwoluzky, Alexander, "Pre-announcement and Timing: The Effects of a Government Expenditure Shock," European Economic Review 56 (April 2012), 373-388.

Leduc, Sylvain, and Wilson, Daniel J. "Roads to Prosperity or Bridges to Nowhere? Theory and Evidence on the Impact of Public Infrastructure Investment." NBER Macroeconomics Annual 27 (2013), 89-142.

Leeper, Eric M., Richter, Alexander, W., and Walker, Todd B., "Quantitative Effects of Fiscal Foresight." American Economic Journal: Economic Policy 4 (May 2012), 115-144.

Leeper, Eric M., Walker, Todd B., and Yang, Shu-Chun Susan, "Fiscal Foresight And Information Flows," Econometrica 81/3 (May 2013), 1115-1145.

Mertens, Karel, and Ravn, Morten O. "Understanding the aggregate effects of anticipated and unanticipated tax policy shocks," Review of Economic Dynamics 14 (2011), 27-54.

Mertens, Karel, and Ravn, Morten O. "Empirical Evidence on the Aggregate Effects of Anticipated and Unanticipated U.S. Tax Policy Shocks." American Economic Journal: Economic Policy 4 (May 2012), 145-181.

Perotti, Roberto. "The Effects of Tax Shocks on Output: Not So Large, But Not Small Either." American Economic Journal: Economic Policy 4 (May 2012), 214-237.

Romer, Christina D. and Romer, David H., "The Macroeconomic Effects of Tax Changes: Estimates Based on a New Measure of Fiscal Shocks," American Economic Review 100/3 (June 2010a), 763-801. 
Romer, Christina D. and Romer, David H., "A Narrative Analysis of Postwar Tax Changes," American Economic Association website (June 2010b).

Sinn, Hans-Werner, The Green Paradox: A Supply-Side Approach to Global Warming (Cambridge: MIT Press, 2012).

Van der Ploeg, Frederick, and Cees Withagen, "Global warming and the green paradox: A review of adverse effects of climate policies." Review of Environmental Economics and Policy (2020).

Yang, Shu-Chun Susan. "Quantifying Tax Effects under Perfect Foresight," Journal of Monetary Economics 52 (2005), 1557-1568. 